\title{
Co-expression and prognostic significance of the HER family members, EGFRvIII, C-MET, CD44 in patients with ovarian cancer
}

\author{
Soozana Puvanenthiran ${ }^{1}$, Sharadah Essapen², Ben Haagsma ${ }^{3}$, Izhar Bagwan ${ }^{3}$, \\ Margaret Green ${ }^{3}$, Said Abdullah Khelwatty ${ }^{1}$, Alan Seddon ${ }^{1}$ and Helmout Modjtahedi ${ }^{1}$ \\ ${ }^{1}$ School of Life Sciences, Pharmacy and Chemistry, Kingston University London, Kingston, UK \\ ${ }^{2}$ St Luke's Cancer Centre, Royal Surrey County Hospital, Guildford, UK \\ ${ }^{3}$ Department of Histopathology, Royal Surrey County Hospital, Guildford, UK \\ Correspondence to: Helmout Modjtahedi, email: H.Modjtahedi@Kingston.ac.uk
}

Keywords: ovarian cancer; HER family members; C-MET; CD44; prognosis

Received: November 03, $2017 \quad$ Accepted: March 02, $2018 \quad$ Published: April 13, 2018

Copyright: Puvanenthiran et al. This is an open-access article distributed under the terms of the Creative Commons Attribution License 3.0 (CC BY 3.0), which permits unrestricted use, distribution, and reproduction in any medium, provided the original author and source are credited.

\section{ABSTRACT}

EGFR and HER-2 are important targets but none of the monoclonal antibodies or small molecule tyrosine kinase inhibitors specific for the HER members has been approved for the treatment of patients with ovarian cancers. In some studies, co-expression of other growth factor receptors has been associated with resistance to therapy with the HER inhibitors. The aim of the present study was to determine the relative expression, cellular location, and prognostic significance of HER-family members, the EGFR mutant (EGFRvIII) C-MET, IGF-1R and the cancer stem cell biomarker CD44 in 60 patients with FIGO stage III and IV ovarian cancer. At cut off $>5 \%$ of tumour cells with positive staining, $62 \%, 59 \%, 65 \%$ and $45 \%$ of the cases were EGFR, HER-2, HER-3 and HER-4 positive, and $3 \%, 22 \%$ and $48.3 \%$ of the cases were positive for EGFRvIII, c-MET, and CD44 respectively. Interestingly, $23 \%$ co-expressed all four members of the HER family. On univariate analysis, only EGFR staining at $>50 \%$ of tumour cells (HR $=3.57, p=$ $0.038)$ and $C D 44$ staining at $3+$ intensity $(H R=7.99, p=0.004)$ were associated with a poorer overall survival. EGFR expression $(H R=2.83, p=0.019)$ and its co-expression with HER-2, HER-3, HER-2/HER-3, and C-MET were all associated with poorer diseasefree survival. Our results suggest co-expression of the HER-family members is common in Stage III and IV ovarian cancer patients. Further studies on the prognostic significance and predictive value of all HER family member proteins for the response to treatment with various forms of the HER inhibitors are warranted.

\section{INTRODUCTION}

Despite major advances in our understanding of cancer biology and pathogenesis, cytoreductive surgery, platinum-based chemotherapy and targeted therapy, ovarian cancer remains as one of the world's most aggressive and lethal types of gynecological cancer [1-6]. Worldwide, an estimated 238,700 women were diagnosed with ovarian cancer, and 152,000 died of the disease in 2012 [7]. As there are currently no reliable screening methods and the early stages of the disease usually present no obvious symptoms, the great majority of ovarian cancer patients are diagnosed at advanced stages of the disease $[8,9]$. While the five-year survival rate for ovarian cancer patients diagnosed at stage I and II of the disease is approximately $90 \%$ and $65 \%$ respectively, it reduces to around $33 \%$ and $18 \%$ for patients diagnosed at stage III and stage IV respectively $[10,11]$. Moreover, in spite of initial chemo-sensitivity, most ovarian cancers acquire a drug-resistant phenotype, which in turn makes it largely a recurrent and incurable disease $[6,9,12,13]$. These statistics highlight the urgent need for the identification of marker(s), which are important in the progression of ovarian cancer, for use in the early detection of the 
disease, and for guiding treatment [14]. It is also important to develop novel, more effective and less toxic therapies for patients with ovarian cancer [9, 13, 15-17].

In the past three decades, increased expression or activation of the epidermal growth factor receptor (EGFR) family (also called ErbB/HER family) have been reported in a wide range of epithelial cancers, and in some studies have also been associated with a poorer prognosis and resistance to therapeutic options [18-22]. The HER family members includes, EGFR, HER-2, HER-3 and HER-4. Homodimersiation and heterodimerisation of the HER family members, as a result of ligand binding and or receptor mutation, results in the activation of several downstream cell signaling pathways and ultimately tumour cell proliferation, reduced apoptosis, tumour migration and invasion, as well as resistance to therapy $[19,22,23]$. To date, several types of HER inhibitors have been approved for the treatment of patients with a wide range of epithelial cancers including the anti-EGFR monoclonal antibodies (mAbs) cetuximab, panitumumab, necitumumab and nimotuzumab, anti-HER mAbs trastuzumab, pertuzumab and ado-trastuzumab emtansine, and small molecule tyrosine kinase inhibitors (TKIs) such as EGFR specific erlotinib and gefitinib, dual EGFR/HER-2 TKI lapatinib, and pan HER-family TKIs afatinib and neratinib [24-26]. Despite these advances, many patients simply do not respond or eventually develop resistance to therapy with the EGFR inhibitors, and none of the HER inhibitors have yet been approved for the treatment of ovarian cancer patients [27-34]. In some studies, tumour heterogeneity, expression of other members of the HER family (e.g. HER-3), mutation of a HER family member (e.g. the EGFRvIII), the co-expression of other heterologous growth factor receptors (e.g. c-MET, IGF-1R), and the presence of cancer stem cells has been suggested as possible mechanisms of resistance to therapy with the HER inhibitors and cytotoxic drugs. These together with poor patient selection may therefore have contributed to the disappointing clinical trials with the HER inhibitors in ovarian cancer [35-43].

We have recently studied the impact of the growth factor receptor expression and the putative ovarian cancer stem cell marker CD44 on the sensitivity of a large panel of human ovarian cancer cells to treatment with various forms of HER-TKIs (Gefitinib, Erlotinib, Lapatinib, Sapitinib, Afatinib, Canertinib, Neratinib) and other TKIs including crizotinib (C-met/Alk inhibitor), NVP-AEW541 (IGF-1R inhibitor), dasatinib (v-abl/src/c-KIT TKI) and imatinib (v-abl/c-KIT/PDGFR TKI) [33]. Of the HER inhibitors, the irreversible pan-HER TKIs were found to be the most effective for inhibiting the growth and migration of ovarian cancer cells. However, to our knowledge, there is currently no comprehensive study on the relative expression, cellular location and prognostic significance of all members of the HER family, c-MET, IGF-1R, and the putative ovarian cancer stem cell biomarker in patients with ovarian cancer. Therefore, in this study we examined the relative expression and cellular location of all members of the HER family, the type-III mutated form of EGFR (EGFRvIII), c-MET, IGF$1 \mathrm{R}$ and CD44 by immunohistochemistry in patients with FIGO stage III and IV ovarian cancer and their associations with clinico-pathological parameters, overall survival and disease-free survival.

\section{RESULTS}

\section{Clinicopathological characteristics}

Patient clinicopathological characteristics are summarised in Table 1. The mean overall survival in this study was $2.62 \pm 1.7$ years (median 2.3 years), and the mean disease-free survival was $25.2 \pm 20$ months (median 18 months). No association was found with the clinicopathological characteristics and overall survival of these patients. However, overall survival was found to be poorer in the eight patients who received bevacizumab $(p=0.021$, Table 1$)$

\section{Most ovarian cancer cases were HER positive but EGFRvIII negative by immunohistochemistry}

The expression pattern of EGFR, HER-2, HER-3 and HER-4 was determined in 60 FIGO stage III and IV ovarian tumour specimens. At a cut-off value of above $5 \%$ of tumour cells with positive immunostaining, the expression of EGFR was seen in 37/60 (61.7\%) ovarian cancer cases (Table 2). Of these, the cellular location of EGFR staining was membranous and cytoplasmic in $20 / 60(33.3 \%)$, and $17 / 60(28.3 \%)$ of the cases examined respectively, and the intensity of EGFR staining of $2+$ or $3+$ was present in five patients (Table 2, Figure 1). The great majority of tumour specimens $(93 \%)$ were HER2 positive at the cut-off value of above $5 \%$. However, in contrast to EGFR, the cellular location of HER-2 immunostaining was predominantly cytoplasmic (50/60, $83.3 \%$ ) (Table 2, Figure 1). Interestingly, using the RTJ.2 $\mathrm{mAb}$ the cellular location of HER-3 was mostly nuclear and of these, at cut-off value of above $5 \%$ of tumour cells with positive immunostaining was detected in 39/60 (65\%) of the cases examined (Table 2, Figure 1). At the same cut-off value of above $5 \%$ of tumour cells with positive immunostaining, HER-4 expression was detected in $27 / 60(45 \%)$ of the cases examined, with the predominant location of immunostaining being cytoplasmic (43\%) (Table 2, Figure 1). Finally, the expression of EGFRvIII was rare in tumour specimens from these patients and only weak cytoplasmic staining was seen in 3.3\% $(2 / 60)$ of the ovarian cancer cases examined (Table 2, Figure 1). The percentage of positive tumour specimens, at other cutoff values (i.e. above $10 \%, 20 \%$ or $50 \%$ of the tumour cells with positive immunostaining) are summarised and presented in Table 2. 
Table 1: Clinicopathological characteristics and overall survival of FIGO stage III and IV ovarian cancer patients

\begin{tabular}{|c|c|c|c|c|c|}
\hline Characteristics & $\begin{array}{c}\text { Number } \\
\text { of patients } \\
(\%)\end{array}$ & $\begin{array}{c}\text { Overall survival } \\
\text { in years } \\
(\text { mean } \pm \mathrm{SE})\end{array}$ & $p$-value & $\begin{array}{c}\text { Disease free survival } \\
\text { in months } \\
(\text { mean } \pm \mathrm{SE})\end{array}$ & $p$-value \\
\hline \multicolumn{6}{|l|}{ Age in years } \\
\hline$\leq 65$ & $22(36.7)$ & $4.6 \pm 0.2$ & NS & $31.2 \pm 5.7$ & NS \\
\hline$>65$ & $38(63.3)$ & $4.8 \pm 0.2$ & & $46.3 \pm 5.1$ & \\
\hline \multicolumn{6}{|l|}{ Subtypes } \\
\hline Serous & $51(85)$ & $4.7 \pm 0.2$ & NS & $42.8 \pm 4.2$ & NS \\
\hline Non-serous & $9(15)$ & $5.1 \pm 0.4$ & & $23.0 \pm 9.2$ & \\
\hline \multicolumn{6}{|l|}{ FIGO stage } \\
\hline III & $44(73.3)$ & $4.8 \pm 0.3$ & NS & $42.1 \pm 4.8$ & NS \\
\hline IV & $16(26.7)$ & $4.5 \pm 0.1$ & & $35.1 \pm 5.3$ & \\
\hline \multicolumn{6}{|l|}{ Grade } \\
\hline $\mathrm{G} 2$ & $2(3.3)$ & NS & NS & $20.0 \pm 0.0$ & NS \\
\hline G3 & $58(96.7)$ & & & $41.2 \pm 4.1$ & \\
\hline \multicolumn{6}{|c|}{ Bevacizumab treated* } \\
\hline Yes & $8(13.3)$ & $4.3 \pm 0.1$ & 0.021 & $45.4 \pm 6.5$ & NS \\
\hline No & $49(81.7)$ & $5.0 \pm 0.2$ & & $37.7 \pm 4.6$ & \\
\hline
\end{tabular}

NS: not significant $(P>0.05)$,

*data for bevacizumab treated missing in 3 patients. OS and DFS analysis was conducted by omitting the missing data. Overall survival and disease free survival relative to the indicated features was determined by Kaplan-Meier analysis and the log-rank test. $P$-value of $<0.05$ was considered significant.

Table 2: Expression of HER family members, c-MET, IGF-IR and CD44 determined by immunohistochemistry in FIGO stage III and IV ovarian cancer patients, data are presented based on the percentage of tumour cells with positive staining, the intensity of staining and the cellular location of staining

\begin{tabular}{|c|c|c|c|c|c|c|c|}
\hline \multicolumn{8}{|c|}{ No. of positive tumours (\%) } \\
\hline Scoring criteria & EGFR & HER-2 & HER-3 & HER-4 & EGFRvIII & c-MET & CD44 \\
\hline \multicolumn{8}{|c|}{ Percentage of positive tumour cells ( $\%)$} \\
\hline$>5$ & $37(61.7)$ & $56(93.3)$ & $39(65)$ & $27(45)$ & $2(3.3)$ & $13(21.7)$ & $29(48.3)$ \\
\hline$>10$ & $29(48.3)$ & $55(91.7)$ & $37(61.7)$ & $17(28.3)$ & 0 & $7(11.7)$ & $11(18.3)$ \\
\hline$>\mathbf{2 0}$ & $25(41.7)$ & $50(83.3)$ & $33(55)$ & $10(16.7)$ & 0 & $7(11.7)$ & $10(16.7)$ \\
\hline$>\mathbf{5 0}$ & $12(20)$ & $44(73.3)$ & $18(30)$ & $3(5)$ & 0 & $5(8.3)$ & $4(6.7)$ \\
\hline \multicolumn{8}{|l|}{ Intensity } \\
\hline $1+$ & $32(53.2)$ & $19(31.7)$ & $28(46.7)$ & $25(41.7)$ & $2(3.3)$ & $9(15)$ & $7(11.7)$ \\
\hline $2+$ & $4(6.7)$ & $25(41.7)$ & $19(31.7)$ & $2(3.3)$ & 0 & $4(6.7)$ & $13(21.7)$ \\
\hline $3+$ & $1(1.7)$ & $12(20)$ & $5(8.3)$ & $1(1.7)$ & 0 & 0 & $10(16.7)$ \\
\hline \multicolumn{8}{|c|}{ Sub-cellular localisation } \\
\hline Membranous & $20(33.3)$ & $6(10)$ & 0 & $2(3.3)$ & 0 & 0 & $30(50)$ \\
\hline Cytoplasmic & $17(28.3)$ & $50(83.3)$ & 0 & $26(43.3)$ & $2(3.3)$ & $13(21.7)$ & 0 \\
\hline Nuclear & 0 & 0 & $40(66.7)$ & 0 & 0 & 0 & 0 \\
\hline
\end{tabular}

All tumours were IGF-IR negative

\section{Expression level of IGF-1R, c-MET and CD44 determined by immunohistochemistry}

Next, we examined the expression pattern of other growth factor receptors (c-MET and IGF-1R) and one of the putative ovarian cancer stem cell markers, CD44, in tumour specimens from these patients. Interestingly, while the anti-IGF-1R Clone 24-31 mAb stained the IGF-1R positive control placenta, none of the 60 ovarian cancer specimens were IGF-1R positive (Table 2, Figure 1). At 

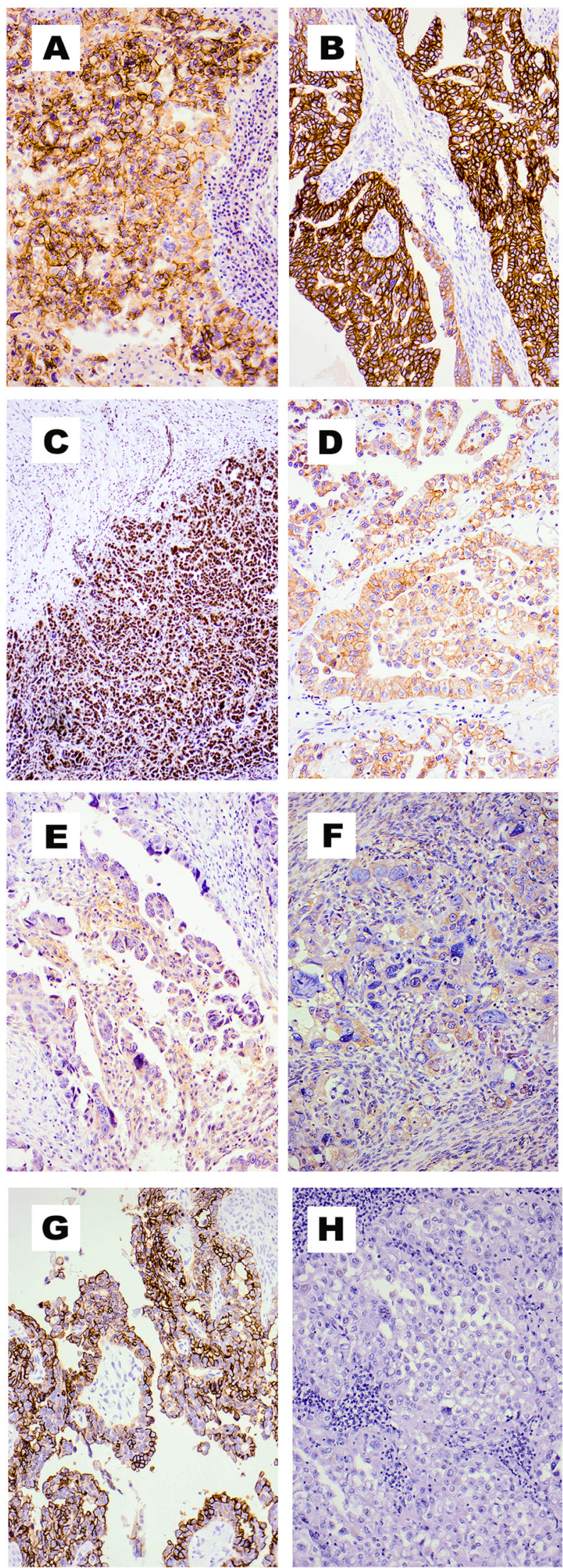

Figure 1: Immunohistochemical staining of tumour specimens from patients with stage III and IV ovarian cancer. EGFR 2+/3+ membranous (A), HER-2 2+ membranous (B), HER-3 3+ nuclear (C) HER-4 2+ membranous (D) EGFRvIII 1+ cytoplasmic (E), c-MET 2+ cytoplasmic (F), CD44 3+ membranous (G), and negative control (H). Magnification x100. 
the cut of value of above 5\% of the tumour cells with positive immunostaining, the expression of c-MET was detected in 13/60 ovarian cancer cases (21.7\%) with its cellular location all being cytoplasmic (Table 2, Figure 1). The cellular location of CD44 staining was only membranous. At cut-off value of above $5 \%$ of tumour cells with positive immunostaining, $48 \%$ of the ovarian cancer cases were CD44 positive (Table 2, Figure 1). The percentage of positive cases at other cut-off values and based on the intensity of immunostaining for these biomarkers are summarised in Table 2.

\section{Co-expression of different members of the HER family in patients with ovarian cancer}

While various studies have examined and reported the expression level of the individual members of the HER family, the number of studies on the co-expression of these receptors are limited. Therefore, next the coexpression of HER family members, c-MET, and CD44 were analysed, and the results are summarised in Table 3 . For example, at cut of values of above $5 \%$ of tumour cells with positive staining, dual expression of EGFR/ HER-2, EGFR/HER-3 and EGFR/HER-4 were present at $62 \%, 45 \%$, and $28 \%$ of the cases examined respectively (Table 3 ). In addition, $43 \%, 23 \%$ and $28 \%$ of the cases had co-expression of EGFR/HER-2/HER-3, EGFR/ HER-3/HER-4 and EGFR/HER-2/HER-4 respectively. Interestingly, of the 60 cases examined, $23 \%$ had coexpression of all four members of the HER family (Table 3 ). In $3 \%$ and $12 \%$ of the cases examined, the coexpression of all four members of the HER family was also accompanied by expression of c-MET and CD44 respectively (Table 3 ).

\section{CD44 expression with $3+$ intensity is associated with a poorer overall survival}

The association between the expression level of HER family members, at different cut-off values, the intensity of staining and the cellular location of staining and overall survival were determined using the KaplanMeier curves and log ranks-test. EGFR expression at $>50 \%$ of tumour cells with positive EGFR immunostaining was associated with poorer overall survival $(p=0.020)$ (Figure 2A). When using univariate analysis, patients with EGFR expression at cut-off values of $>50 \%$ had a hazard ratio of 3.6 (CI $1.07-11.85 p=0.038$, Table 4), however the expression of EGFR $>50 \%$ did not remain as an independent prognostic factor in multivariate analysis after adjusting for other covariates used in this study (HR 3.8, CI 0.95-15.6, $p=0.058$, Table 4). No significant association was found between the expression of HER member's at other cut-off values and the overall survival in these patients, and nor between EGFRvIII expression and the overall survival (data not shown).
While there was no significant association between CD44 immunostaining at cut-off values $>5 \%,>10 \%$ and $>20 \%$ and overall survival, CD44 immunostaining of $3+$ intensity at cut-off values of $>5 \%$ of tumour cells was associated with poorer overall survival in these patients $(3.66 \pm 0.39$ vs. $5.01 \pm 0.20)(p<0.0001)$ (Figure $2 \mathrm{~A})$. Using univariate analysis, we found an 8 fold increased risk of poorer overall survival with the expression of CD44 $3+$ intensity at $>5 \%$ cut-off value $(p=0.004)$ and this remained an independent prognostic factor for survival in multivariate analysis in this study ( $p=0.007$, Table 4$)$.

\section{Impact of HER family members, c-MET and CD44 expression on disease-free survival}

Of all cut-off values used in this study, only the EGFR positive immunostaining at cut-off values of $>5 \%$ and $>10 \%$ of the tumour cells were significantly associated with a poorer disease-free survival (32.34 \pm 4.88 vs $53.79 \pm 5.78$ months, $p=0.014$ Figure 2B) and $(29.64 \pm 4.86$ vs $47.9 \pm 5.05$ months, $p=0.026$, data not shown). There was no significant association between HER-2 positive immunostaining at all cut-off values and disease-free survival in these ovarian cancer cases. However, HER-4 positive immunostaining in $>10 \%$ of the tumour cells was associated with a better disease-free survival (53.43 \pm 6.50 vs. $36.0 \pm 4.3$ months, $p=0.042)$ in these patients (Figure 2B).

Moreover, there was no significant association between the expression of c-MET alone at all cut-off values $(>5 \%,>10 \%,>20 \%$ and $>50 \%)$ and disease-free survival. Interestingly, at cut-off values $>5 \%$ of the tumour cells with positive staining, the co-expression of EGFR/ HER-2, EGFR/HER-3, EGFR/c-MET, and EGFR/HER2/HER-3 were all associated with a poorer disease freesurvival in the univariate analysis (Figure 2B, Table 4). Using multivariate analysis, with the exception of EGFR/ c-MET co-expression, the co-expression of the HERfamily members remained independent prognostic factors of DFS in this study (Table 4).

\section{DISCUSSION}

Ovarian cancer is a leading cause of death from gynaecological cancers $[44,45]$. Most ovarian cancer cases are currently diagnosed at advanced stages of the disease (III and IV) with tumour recurrence and chemoresistance as the major causes of the treatment failure [16]. Therefore, there is an urgent need for the identification of biomarkers for use in the early diagnosis of ovarian cancer, determining prognosis, and predicting response to therapy [46]. Moreover, it is essential to develop more effective and less toxic targeted therapies for patients diagnosed with ovarian cancer $[2,9,47]$.

In the past three decades, abnormal expression and increased activation of members of the HER family have 
Table 3: Co-expression of HER family members, c-MET, and CD44 determined by immunohistochemistry in patients with FIGO stage III and IV ovarian cancer. The percentage was scored based on the cut of value of above $5 \%$ of tumour cells with positive staining

\begin{tabular}{lccc}
\hline Markers & $\begin{array}{c}\text { No. of positive } \\
\text { tumours (\%) }\end{array}$ & Markers & $\begin{array}{c}\text { No. of positive tumours } \\
\text { (\%) }\end{array}$ \\
\hline EGFR/HER-2 & $37(61.7)$ & HER-2/HER-4/C-MET & $5(8.3)$ \\
EGFR/ HER-3 & $27(45)$ & HER-3/HER-4/C-MET & $3(5)$ \\
EGFR/HER-4 & $17(28.3)$ & EGFR/HER-2/HER-3/C-MET & $6(10)$ \\
EGFR/HER-2/HER-3 & $26(43.3)$ & EGFR/HER-2/HER-4/C-MET & $2(3.3)$ \\
EGFR/HER-3/HER-4 & $14(23.3)$ & EGFR/HER-2/HER-3/HER-4/C-MET & $2(3.3)$ \\
EGFR/HER-2/HER-4 & $17(28.3)$ & EGFR/CD44 & $17(28.3)$ \\
EGFR/HER-2/HER-3/HER-4 & $14(23.3)$ & HER-2/CD44 & $28(46.7)$ \\
HER-2/HER-3 & $37(61.7)$ & HER-3/CD44 & $17(28.3)$ \\
HER-2/HER-4 & $26(43.3)$ & HER-4/CD44 & $14(23.3)$ \\
HER-3/HER-4 & $19(31.7)$ & EGFR/HER-2/CD44 & $17(28.3)$ \\
EGFR/C-MET & $8(13.3)$ & EGFR/HER-3/CD44 & $11(18.3)$ \\
HER-2/C-MET & $13(21.7)$ & EGFR/HER-4/CD44 & $9(15)$ \\
HER-3/C-MET & $9(15)$ & HER-2/HER-3/CD44 & $17(28.3)$ \\
HER-4/C-MET & $5(8.3)$ & HER-2/HER-4/CD44 & $13(21.7)$ \\
EGFR/HER-2/C-MET & $8(13.3)$ & HER-3/HER-4/CD44 & $9(15)$ \\
EGFR/HER-3/C-MET & $6(10)$ & EGFR/HER-2/HER-3/CD44 & $11(18.3)$ \\
EGFR/HER-4/C-MET & $2(3.3)$ & EGFR/HER-2/HER-4/CD44 & $7(11.7)$ \\
HER-2/HER-3/C-MET & $9(15)$ & EGFR/HER-2/HER-3/HER-4/CD44 & $7(11.7)$ \\
\hline
\end{tabular}

been reported in a wide range of human malignancies and of these EGFR and HER-2 are important therapeutic targets for treatment with several monoclonal antibody based products and different forms of the HER inhibitors in a wide range of cancers. However, clinical trials with the HER inhibitors in patients with ovarian cancer have been disappointing and none of the HER inhibitors has yet been approved for the treatment of patients with ovarian cancer. This may be due to the lack of studies examining the relative expression, cellular location, prognostic significance and predictive value of all members of the HER family proteins in patients with ovarian cancer [48-50]. Indeed, as trans-activation of the HER family members through hetero/homodimerization can contribute to tumourigenesis, and human cancers, including ovarian cancer are heterogeneous in nature, it is considered to be essential to determine the relative expression of all members of the HER family in patients with ovarian cancer [51]. Also the interaction between the HER family members and other tyrosine kinases may be another route for promoting oncogenic signaling pathways and maintaining cancer cell survival and proliferation. Therefore, in this comprehensive study for the first time to our knowledge, we investigated the co-expression and cellular location of all members of the HER-family, as well as the EGFRvIII, c-MET and IGF-1R, and putative CSC marker CD44 in 60 patients with FIGO stages III and
IV. We also investigated their impacts on overall survival and disease-free survival.

Several studies examined the expression level of the individual member of the HER family in patients with ovarian cancer. The expression of EGFR, HER-2, HER-3 and HER-4 reported in the literature for ovarian cancer exhibits wide variation ranging from $9-90 \%, 6.4-52 \%$, $16-69 \%$, and $65-90 \%$ of the cases examined respectively, with EGFRvIII expression being rare [52-59]. In this study of 60 FIGO stage III and IV patients, the expression levels of the EGFR and HER-2 were determined by immunohistochemistry using mAb EGFR.113 and $\mathrm{mAb}$ $3 \mathrm{~B} 5$ respectively. At cut off value of $>5 \%$ of tumours with positive staining, EGFR and HER-2 expression was detected in $62 \%$ and $93 \%$ of the ovarian cancer cases respectively (Table 2). Of these, the cellular location of EGFR staining was membranous and cytoplasmic in $33 \%$ and $28 \%$ of the cases examined, whereas HER-2 immunostaining was predominantly cytoplasmic $(83.3 \%)$ with only $10 \%$ of the cases having membranous expression of HER-2 (Table 2). The results of a meta-analysis of 15 studies involving 2471 patients with ovarian cancer for the EGFR expression found positive EGFR immunostaining in $6.2 \%$ to $72.6 \%$ (median $35 \%$ ) of tumours, and in 7 studies (63.6\%) EGFR expression was found to be predictive of a poorer overall survival [60]. In the same study, the authors also carried out a meta-analysis of 20 
studies involving 3055 patients for the HER-2 expression and found positive immunostaining for HER-2 in 5\% to $57 \%$ (median $18 \%$ ) of the cases examined, and 8 out of 20 studies (40\%) found HER-2 positivity to be of a significant predictor of overall survival in univariate analysis [60]. This wide variation in the expression level of HER family members is common in ovarian cancer and could be due to the use of various techniques, various antibodies employed for the immunohistochemical detection of such receptors, different scoring system, as well as different patient and population size. Unlike EGFR and HER-2, very few studies have been conducted on HER-3 and HER-4 expression in ovarian cancers and in particular the coexpression all four members of the HER family and their prognostic significance [61-63]. Of the 60 stage III and IV ovarian cases examined here, we found $65 \%$ and $45 \%$ to be HER-3 and HER-4 positive respectively. Interestingly, the predominant location of HER-3 and HER-4 staining were found to be nuclear (67\%), and cytoplasmic (43\%) respectively (Table 2). Nuclear expression of HER-3 has also been reported in other types of cancer and associated with increased risk of disease progression [64].

Interestingly, $23 \%$ of the cases had co-expression of all four members of the HER family and 43\%, 23\% and $28 \%$ of the cases had co-expression of three members of the HER family namely EGFR/HER-2/HER-3, EGFR/ HER-3/HER-4 and EGFR/HER-2/HER-4 (Table 3). When examined at different cut off values, only EGFR staining at $>50 \%$ of tumour cells $(\mathrm{HR}=3.57, \mathrm{CI}=1.07-11.85$, $p=0.038$ ) was associated with a poorer overall survival in univariate analysis and EGFR expression at $>5 \%$ of tumour cells $(\mathrm{HR}=2.83, p=0.019)$ and its co-expression

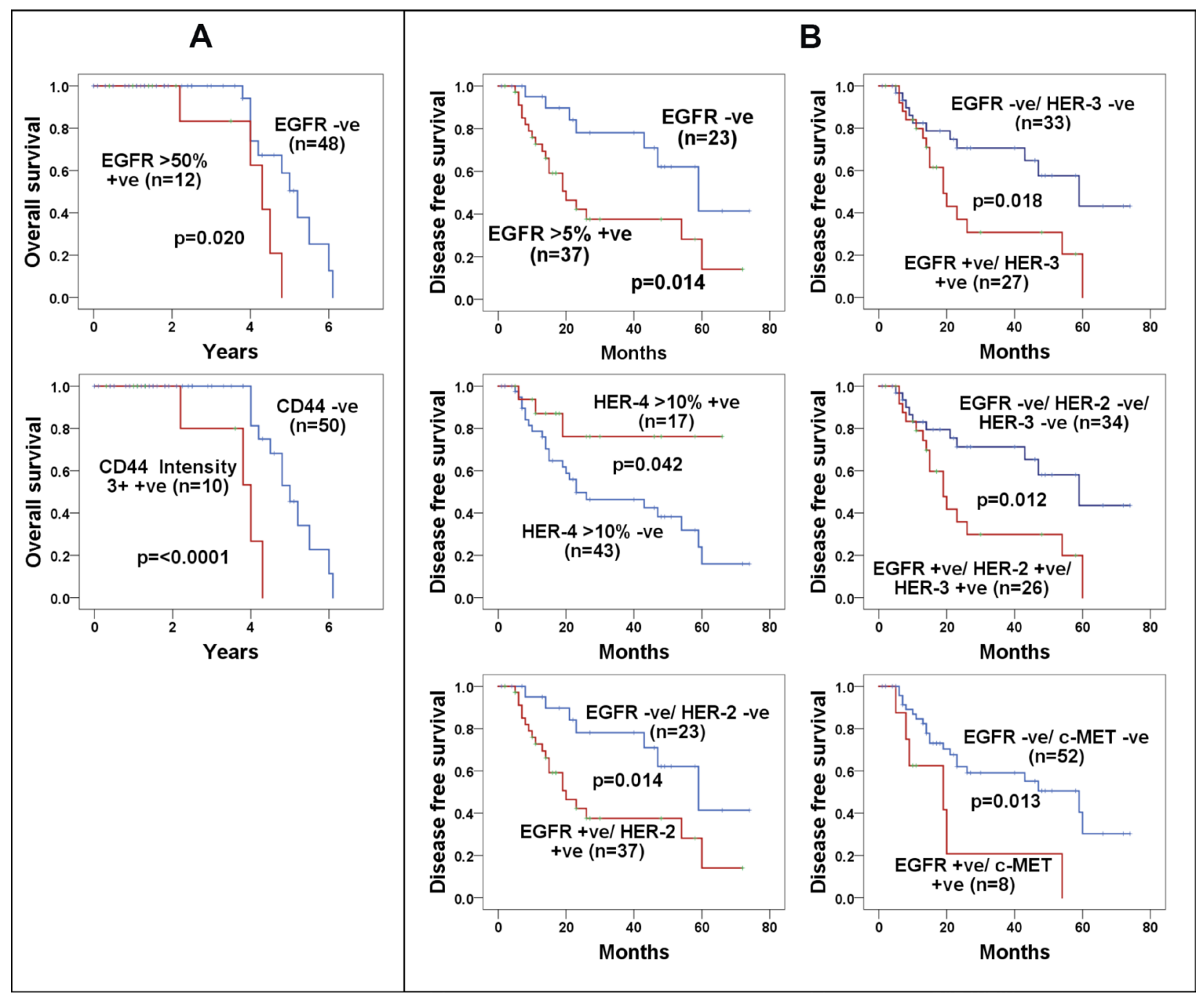

Figure 2: The impact of various biomarker expressions on the overall survival and disease free survival in patients with stages III and IV ovarian cancer. (A) Kaplan-Meier survival curves of the overall survival for the patients with EGFR staining in $>50 \%$ of tumour cells, and CD44 staining of $3+$ intensity in $>5 \%$. (B) Kaplan-Meier survival curves of the disease free survival for the patients with total expression of EGFR staining of $>5 \%$ of tumour cells, HER-4 staining of $>10 \%$ tumour cells, EGFR \& HER-2 coexpression $>5 \%$ tumour cells, EGFR \& HER-3 co-expression $>5 \%$ tumour cells, EGFR \& HER-2 \& HER-3 co-expression $>5 \%$ tumour cells, EGFR \& c-MET co-expression of $>5 \%$ tumour cells. A log-rank test value of P- $<0.05$ was considered statistically significant. 
Table 4: Univariate and multivariate analysis of the association between sub-categories of biomarkers in overall survival and the disease free survival

\begin{tabular}{|c|c|c|c|c|c|c|}
\hline \multirow[t]{2}{*}{ Overall Survival } & \multicolumn{3}{|c|}{ Univariate } & \multicolumn{3}{|c|}{ Multivariate } \\
\hline & Hazard Ratio & $95 \%$ CI & $P$-value & Hazard Ratio & $95 \%$ CI & $P$-value \\
\hline EGFR $>5 \%$ & 1.15 & $0.41-3.21$ & $0.787(\mathrm{NS})$ & 1.02 & $0.31-3.31$ & $0.964(\mathrm{NS})$ \\
\hline HER-2 $>5 \%$ & 0.61 & $0.13-2.81$ & $0.531(\mathrm{NS})$ & 0.41 & $0.07-2.19$ & 0.298 (NS) \\
\hline HER-3 $>5 \%$ & 0.43 & $0.16-1.30$ & $0.146(\mathrm{NS})$ & 0.36 & $0.16-1.15$ & $0.088(\mathrm{NS})$ \\
\hline HER-4 >5\% & 1.85 & $0.63-5.37$ & $0.256(\mathrm{NS})$ & 0.26 & $0.59-6.55$ & $0.266(\mathrm{NS})$ \\
\hline c-MET $>5 \%$ & 1.23 & $0.33-4.50$ & $0.748(\mathrm{NS})$ & 1.10 & $0.29-4.21$ & $0.883(\mathrm{NS})$ \\
\hline CD44 $>5 \%$ & 1.08 & $0.38-3.06$ & $0.882(\mathrm{NS})$ & 1.12 & $0.39-3.24$ & $0.823(\mathrm{NS})$ \\
\hline EGFR $>50 \%$ & 3.57 & $1.07-11.85$ & 0.038 & 3.85 & $0.95-15.6$ & $0.058(\mathrm{NS})$ \\
\hline CD44 >5\% 3+ & 7.99 & $1.96-32.55$ & 0.004 & 9.23 & $1.82-46.7$ & 0.007 \\
\hline \multicolumn{7}{|l|}{ Disease free survival } \\
\hline EGFR $>5 \%$ & 2.83 & $1.18-6.77$ & 0.019 & 2.53 & $1.00-6.36$ & 0.048 \\
\hline HER-2 $>5 \%$ & 1.73 & $0.40-7.36$ & $0.455(\mathrm{NS})$ & 2.44 & $0.31-6.22$ & $0.660(\mathrm{NS})$ \\
\hline HER-3 $>5 \%$ & 0.41 & $0.61-3.27$ & 0.414 (NS) & 1.39 & $0.64-3.63$ & $0.341(\mathrm{NS})$ \\
\hline HER-4 > 5\% & 0.45 & $0.19-1.07$ & $0.073(\mathrm{NS})$ & 1.51 & $0.21-1.27$ & $0.151(\mathrm{NS})$ \\
\hline c-MET $>5 \%$ & 1.45 & $0.61-3.45$ & $0.398(\mathrm{NS})$ & 1.50 & $0.62-3.60$ & $0.362(\mathrm{NS})$ \\
\hline CD44 >5\% & 0.87 & $0.40-1.86$ & $0.721(\mathrm{NS})$ & 0.95 & $0.43-2.06$ & $0.896(\mathrm{NS})$ \\
\hline EGFR $>10 \%$ & 2.40 & $1.07-5.37$ & 0.032 & 2.44 & $1.06-5.60$ & 0.035 \\
\hline EGFR + HER-2 >5\% & 2.83 & $1.18-6.77$ & 0.019 & 2.53 & $1.00-6.36$ & 0.048 \\
\hline EGFR + HER-3 $>5 \%$ & 2.48 & $1.13-5.42$ & 0.023 & 2.69 & $1.15-6.28$ & 0.021 \\
\hline $\begin{array}{l}\text { EGFR + HER-2 } \\
+ \text { HER-3 >5\% }\end{array}$ & 2.60 & $1.19-5.67$ & 0.016 & 2.82 & $1.22-6.50$ & 0.015 \\
\hline EGFR + c-MET $>5 \%$ & 3.05 & $1.20-7.75$ & 0.019 & 2.65 & $0.96-7.31$ & $0.059(\mathrm{NS})$ \\
\hline
\end{tabular}

HR: Hazard ratio; 95\% CI: 95\% confidence interval; $p$-value $<0.05$, NS: non-significant.

$P$-value of $<0.05$ was considered significant.

with HER-2 (HR $=2.83, p=0.019)$, HER-3 $(\mathrm{HR}=2.48$, $p=0.023)$, and HER-2/HER-3 (HR $=2.60, p=0.016)$, were all associated with poorer disease-free survival (Table 4, Figure 2). While, at the cut off value of $>5 \%$ of tumour cells with positive immunostaining, $48 \%$ and $22 \%$ the cases were CD44 and c-MET positive respectively, only CD44 immunostaining of 3+ intensity was associated with a poorer overall survival in both univariate and multivariate analysis, and the c-MET/EGFR co-expression $(\mathrm{HR}=3.05, p=0.019)$ was associated with a poorer disease-free survival (Table 4). Interestingly, only one other study to our knowledge, has determined the relative expression of all four HER family members and c-MET in tissue arrays from 202 tumours from ovarian cancer patients (172 FIGO stages I-IV and 30 stages unknown). They found membranous expression of EGFR, HER-2, HER-3, and c-MET in $25 \%, 35 \%, 76 \%$, and $96 \%$ of the cases examined [65]. HER-4 was found to be positive in $98 \%$ of the cases examined, where immunostaining was based upon membrane, cytoplasmic or nuclear staining. They did not find any significant association between the expression levels of these growth factor receptors and
PFS in both univariate analysis and multivariate analysis [65]. More recently, Mehner and colleagues reported the result of immunohistochemical staining of EGFR in tissue microarrays from 488 ovarian cancer patients. They found while $90 \%$ of their tumor specimens had some EGFR staining and 53\% had membranous staining, the EGFR staining alone was not of prognostic value [59]. Also, there is currently conflicting data on the prognostic significance of CD44 in patients with ovarian cancer. While CD44 expression was associated with unfavorable prognostic outcome in FIGO III and IV ovarian cancer in one study [66], Zhang and colleagues reported no correlation between CD44 expression and prognosis in advanced stage ovarian cancer [67]. In another study involving 96 patients with serous ovarian epithelial cancer stages IIBIVA, $49 \%$ of the cases were CD44 positive and this was associated with a statistically significant shorter DFS and overall survival in such patients (HR 6.8, 2-4-19.2 $p \leq 0.001$ ) [68]. The expression of aldehyde dehydrogenase (ALDH1), which is another putative ovarian cancer stem cell biomarker, has also been correlated with significantly lower progression free survival and the maintenance of 
ovarian cancer cell like properties in ovarian cancer patients [69, 70], highlighting the importance of cotargeting of ovarian cancer stem cells in combination with other therapeutics in ovarian cancer. Surprisingly, none of the 60 cases examined in our study was found to be IGF-1R positive. There are currently very few studies of IGF-1R in ovarian cancer patients. While an earlier study reported that of 80 ovarian cancer cases (FIGO I-IV), only $9(11 \%)$ of patients were IGF-1R positive [71], more recent studies have shown that IGF-1R expression was high $(>50 \%)$ particularly in high-grade ovarian cancer cases [72-74].

In summary, our results suggest that co-expression of two, three or all four HER-family members and CD44 overexpression are common in patients with Stages III and IV ovarian cancers and that EGFR and CD44 expression at different cut off values may be of prognostic value. However, further investigations involving a larger group of ovarian cancer patients are warranted to confirm the prognostic value of co-expression of HER family members in patients with ovarian cancer. Moreover, as the targets for therapeutic interventions with monoclonal antibody-based products and small molecules HER TKIs are the HER family proteins and not HER genes, further examination of tumour specimens from ovarian cancer patients in clinical trials with various types of HER inhibitors are warranted. Such studies would help to determine whether the expression of all four HER proteins would be a more reliable predictive biomarker(s) for stratification of ovarian cancer patients who would benefit from therapy with various types of the HER inhibitors [46].

\section{MATERIALS AND METHODS}

\section{Patient information}

Ethical approval was obtained from the Research and Development Committee of the Royal Surrey County Hospital for examination of tumour specimens from patients with ovarian cancer for use in this study. Sixty patients with FIGO stage III and IV ovarian cancer were included in this retrospective study. All patients had radical surgery and cycles of chemotherapy (paclitaxel, carboplatin and gemcitabine) and 8 patients received anti-VEGF mAb bevacizumab between 2009 and 2013. As only archived tumour specimens were included in this study, the ethics committee waived the need for patient consent and patient records/information were analysed anonymously. Those cases with no follow-up information, and poor or insufficient tumour blocks were excluded from this study.

\section{Immunohistochemistry}

The following primary antibodies were used in this study: mouse anti-EGFR (1:10, Novacastra, UK), mouse
anti-HER-2 (1:150, Insight Biotechnology, UK), mouse anti-HER-3 RTJ.2 (1:50, Insight Biotechnology, UK), rabbit anti-HER-4 (1:20, Fisher Scientific, UK), rabbit anti-EGFRvIII (1:150, Bioss Antibodies, UK), mouse antiIGF-1R (4 ug/mL, Merck Millipore, UK), mouse anti-cMET (1:500, Novacastra, UK) and mouse anti-CD44 (1:40, DAKO, UK). Formalin-fixed paraffin-embedded (FFPE) sections of tumour specimens $(3 \mu \mathrm{M})$ were cut in serial sections, and then subjected to antigen retrieval and incubation with primary antibodies as described previously by Khelwatty and colleagues [22]. The optimisation for HER-3 and IGF-1R staining was conducted using the MCF-7 (HER-3+) breast cancer cell line and tumour section of the placenta respectively. Staining of the slides was carried out on a Ventana Benchmark Ultra autostainer with the Ultra View DAB kit (Roche, UK). Following this, all slides were rehydrated and counterstained with haematoxylin, mounted and cover slipped.

\section{Scoring system}

In this study, the immunostaining of the tumour sections were scored based on the percentage of tumour cells that had positive immunostaining at different cutoff values (i.e. $>5 \%,>10 \%,>20 \%$ and $>50 \%$ ) and the intensity of immunostaining (i.e negative 0 , weak positive $1+$, moderate positive $2+$ and strongly positive $3+$ ). The immunostaining was also scored based on the cellular location of the antigen i.e. whether the staining was predominantly present in the membrane, cytoplasm or nucleus of the cells. Two independent trained observers, without prior knowledge of the clinicopathological parameters, conducted the scoring and any disparity in scoring was resolved by simultaneous reassessment of the staining by both observers.

\section{Statistical analysis}

The Chi-Squared test (Pearson Chi-square) and Fisher's exact test were used to investigate the association between immunohistochemistry score and patient clinicopathological data. Kaplan-Meier survival plots and log-rank tests were used to analyse the differences between the groups. The Cox-regression model was used to perform univariate and multivariate analyses. For the multivariate analysis age, FIGO stage, grade and serous subtype were used simultaneously as covariates for both overall survival and disease-free survival, and $\mathrm{P} \leq 0.05$ was considered statistically significant. All statistical analysis were carried out using the PASW Statistics 23 (SPSS Inc), as described in our previous studies [22].

\section{ACKNOWLEDGMENTS}

This work was supported by the GRACE charity (UK), and Kingston University London towards a 
PhD project. HM and SE conceived and designed the experiments. SP performed the experiments, and data analysis. SP, HM, SE, BH, IB and AS and SK helped with technical training and data analysis. SP and HM wrote the paper and SE, AS, BH, IB, SE went through the manuscript, edited and approved the final version of the manuscript.

\section{CONFLICTS OF INTEREST}

No potential conflicts of interest disclosed

\section{FUNDING}

This work was supported by the GRACE charity (UK), and Kingston University London, United Kingdom.

\section{REFERENCES}

1. Colombo PE, Fabbro M, Theillet C, Bibeau F, Rouanet $\mathrm{P}$, Ray-Coquard I. Sensitivity and resistance to treatment in the primary management of epithelial ovarian cancer. Crit Rev Oncol Hematol. 2014; 89:207-16. https://doi.org/10.1016/j. critrevonc.2013.08.017.

2. Nick AM, Coleman RL, Ramirez PT, Sood AK. A framework for a personalized surgical approach to ovarian cancer. Nat Rev Clin Oncol. 2015; 12:239-45. https://doi. org/10.1038/nrclinonc.2015.26.

3. Webber K, Friedlander M. Chemotherapy for epithelial ovarian, fallopian tube and primary peritoneal cancer. Best Pract Res Clin Obstet Gynaecol. 2017; 41:126-138. https:// doi.org/10.1016/j.bpobgyn.2016.11.004.

4. Bookman MA. Optimal primary therapy of ovarian cancer. Ann Oncol. 2016; 27 Suppl 1:i58-i62. https://doi. org/10.1093/annonc/mdw088.

5. Pliarchopoulou K, Pectasides D. Epithelial ovarian cancer: focus on targeted therapy. Crit Rev Oncol Hematol. 2011; 79:17-23. https://doi.org/10.1016/j.critrevonc.2010.07.004.

6. Bast RC Jr, Hennessy B, Mills GB. The biology of ovarian cancer: new opportunities for translation. Nat Rev Cancer. 2009; 9:415-28. https://doi.org/10.1038/nrc2644.

7. Ferlay J, Soerjomataram I, Dikshit R, Eser S, Mathers C, Rebelo M, Parkin DM, Forman D, Bray F. Cancer incidence and mortality worldwide: sources, methods and major patterns in GLOBOCAN 2012. Int J Cancer. 2015; 136:E359-86. https://doi.org/10.1002/ijc.29210.

8. Joyner AB, Runowicz CD. Ovarian cancer screening and early detection. Womens Health (Lond). 2009; 5:693-9. https://doi.org/10.2217/whe.09.65.

9. Narod S. Can advanced-stage ovarian cancer be cured? Nat Rev Clin Oncol. 2016; 13:255-61. https://doi.org/10.1038/ nrclinonc.2015.224.

10. Guppy AE, Nathan PD, Rustin GJ. Epithelial ovarian cancer: a review of current management. Clin Oncol (R Coll Radiol). 2005; 17:399-411.
11. Lutz AM, Willmann JK, Drescher CW, Ray P, Cochran FV, Urban N, Gambhir SS. Early diagnosis of ovarian carcinoma: is a solution in sight? Radiology. 2011; 259:329-45. https://doi.org/10.1148/radiol.11090563.

12. Schorge JO, Eisenhauer EE, Chi DS. Current surgical management of ovarian cancer. Hematol Oncol Clin North Am. 2012; 26:93-109. https://doi.org/10.1016/j. hoc.2011.10.004.

13. Bonneau C, Rouzier R, Geyl C, Cortez A, Castela M, Lis R, Darai E, Touboul C. Predictive markers of chemoresistance in advanced stages epithelial ovarian carcinoma. Gynecol Oncol. 2015; 136:112-20. https://doi.org/10.1016/j. ygyno.2014.10.024.

14. Davidson B, Trope CG. Ovarian cancer: diagnostic, biological and prognostic aspects. Womens Health (Lond). 2014; 10:519-33. https://doi.org/10.2217/whe.14.37.

15. Jelovac D, Armstrong DK. Recent progress in the diagnosis and treatment of ovarian cancer. CA Cancer J Clin. 2011; 61:183-203. https://doi.org/10.3322/caac.20113.

16. Syrios J, Banerjee S, Kaye SB. Advanced epithelial ovarian cancer: from standard chemotherapy to promising molecular pathway targets--where are we now? Anticancer Res. 2014; 34:2069-77.

17. Patch AM, Christie EL, Etemadmoghadam D, Garsed DW, George J, Fereday S, Nones K, Cowin P, Alsop K, Bailey PJ, Kassahn KS, Newell F, Quinn MC, et al. Whole-genome characterization of chemoresistant ovarian cancer. Nature. 2015; 521:489-94. https://doi.org/10.1038/ nature 14410 .

18. Modjtahedi H, Dean C. The receptor for EGF and its ligands - expression, prognostic value and target for therapy in cancer (review). Int J Oncol. 1994; 4:277-96.

19. Gullick WJ. Type I growth factor receptors: current status and future work. Biochem Soc Symp. 1998; 63:193-8.

20. Nicholson RI, Gee JM, Harper ME. EGFR and cancer prognosis. Eur J Cancer. 2001; 37 Suppl 4: S9-15.

21. Mendelsohn J, Baselga J. Status of epidermal growth factor receptor antagonists in the biology and treatment of cancer. J Clin Oncol. 2003; 21:2787-99. https://doi.org/10.1200/ JCO.2003.01.504.

22. Khelwatty SA, Essapen S, Bagwan I, Green M, Seddon AM, Modjtahedi H. Co-expression of HER family members in patients with Dukes' C and D colon cancer and their impacts on patient prognosis and survival. PLoS One. 2014; 9:e91139. https://doi.org/10.1371/journal.pone.0091139.

23. Roskoski R Jr. The ErbB/HER family of protein-tyrosine kinases and cancer. Pharmacol Res. 2014; 79:34-74. https:// doi.org/10.1016/j.phrs.2013.11.002.

24. Modjtahedi H, Ali S, Essapen S. Therapeutic application of monoclonal antibodies in cancer: advances and challenges. Br Med Bull. 2012; 104:41-59. https://doi.org/10.1093/ bmb/lds032.

25. Khelwatty SA, Essapen S, Seddon AM, Modjtahedi H. Prognostic significance and targeting of HER family in 
colorectal cancer. Front Biosci (Landmark Ed). 2013; 18:394-421.

26. Gharwan H, Groninger H. Kinase inhibitors and monoclonal antibodies in oncology: clinical implications. Nat Rev Clin Oncol. 2016; 13:209-27. https://doi.org/10.1038/ nrclinonc.2015.213.

27. Bookman MA, Darcy KM, Clarke-Pearson D, Boothby RA, Horowitz IR. Evaluation of monoclonal humanized anti-HER2 antibody, trastuzumab, in patients with recurrent or refractory ovarian or primary peritoneal carcinoma with overexpression of HER2: a phase II trial of the Gynecologic Oncology Group. J Clin Oncol. 2003; 21:283-90. https:// doi.org/10.1200/JCO.2003.10.104.

28. Lafky JM, Wilken JA, Baron AT, Maihle NJ. Clinical implications of the ErbB/epidermal growth factor (EGF) receptor family and its ligands in ovarian cancer. Biochim Biophys Acta. 2008; 1785:232-65. https://doi.org/10.1016/j. bbcan.2008.01.001.

29. Secord AA, Blessing JA, Armstrong DK, Rodgers WH, Miner Z, Barnes MN, Lewandowski G, Mannel RS; Gynecologic Oncology Group. Phase II trial of cetuximab and carboplatin in relapsed platinum-sensitive ovarian cancer and evaluation of epidermal growth factor receptor expression: a Gynecologic Oncology Group study. Gynecol Oncol. 2008; 108:493-9. https://doi.org/10.1016/j. ygyno.2007.11.029.

30. Modjtahedi H, Essapen S. Epidermal growth factor receptor inhibitors in cancer treatment: advances, challenges and opportunities. Anticancer Drugs. 2009; 20:851-5. https:// doi.org/10.1097/CAD.0b013e3283330590.

31. Wheeler DL, Dunn EF, Harari PM. Understanding resistance to EGFR inhibitors-impact on future treatment strategies. Nat Rev Clin Oncol. 2010; 7:493-507. https:// doi.org/10.1038/nrclinonc.2010.97.

32. Kohler J, Schuler M. Afatinib, erlotinib and gefitinib in the first-line therapy of EGFR mutation-positive lung adenocarcinoma: a review. Onkologie. 2013; 36:510-8. https://doi.org/10.1159/000354627.

33. Puvanenthiran S, Essapen S, Seddon AM, Modjtahedi H. Impact of the putative cancer stem cell markers and growth factor receptor expression on the sensitivity of ovarian cancer cells to treatment with various forms of small molecule tyrosine kinase inhibitors and cytotoxic drugs. Int J Oncol. 2016; 49:1825-38. https://doi.org/10.3892/ ijo.2016.3678.

34. Singh D, Attri BK, Gill RK, Bariwal J. Review on EGFR Inhibitors: Critical Updates. Mini Rev Med Chem. 2016; 16:1134-66.

35. Pautier P, Joly F, Kerbrat P, Bougnoux P, Fumoleau P, Petit T, Rixe O, Ringeisen F, Carrasco AT, Lhomme C. Phase II study of gefitinib in combination with paclitaxel $(\mathrm{P})$ and carboplatin (C) as second-line therapy for ovarian, tubal or peritoneal adenocarcinoma (1839IL/0074). Gynecol Oncol. 2010; 116:157-62. https://doi.org/10.1016/j.ygyno.2009.10.076.

36. Garcia AA, Sill MW, Lankes HA, Godwin AK, Mannel RS, Armstrong DK, Carolla RL, Liepman MK, Spirtos NM, Fischer EG, Leslie KK. A phase II evaluation of lapatinib in the treatment of persistent or recurrent epithelial ovarian or primary peritoneal carcinoma: a gynecologic oncology group study. Gynecol Oncol. 2012; 124:569-74. https://doi. org/10.1016/j.ygyno.2011.10.022.

37. Kaye SB, Poole CJ, Danska-Bidzinska A, Gianni L, Del Conte G, Gorbunova V, Novikova E, Strauss A, Moczko M, McNally VA, Ross G, Vergote I. A randomized phase II study evaluating the combination of carboplatin-based chemotherapy with pertuzumab versus carboplatin-based therapy alone in patients with relapsed, platinum-sensitive ovarian cancer. Ann Oncol. 2013; 24:145-52. https://doi. org/10.1093/annonc/mds282.

38. Coward JI, Middleton K, Murphy F. New perspectives on targeted therapy in ovarian cancer. Int J Womens Health. 2015; 7:189-203. https://doi.org/10.2147/IJWH.S52379.

39. Ledermann JA, Raja FA. Targeted trials in ovarian cancer. Gynecol Oncol. 2010; 119:151-6. https://doi.org/10.1016/j. ygyno.2010.05.008.

40. Sergina NV, Rausch M, Wang D, Blair J, Hann B, Shokat KM, Moasser MM. Escape from HER-family tyrosine kinase inhibitor therapy by the kinase-inactive HER3. Nature. 2007; 445:437-41. https://doi.org/10.1038/ nature 05474.

41. Li X, Duan Y, Qiao C, Zhou T, Yu M, Geng J, Feng J, Shen B, Lv M, Li Y. Anti-HER3 Monoclonal Antibody Inhibits Acquired Trastuzumab-Resistant Gynecologic Cancers. Technol Cancer Res Treat. 2016; 15:573-82. https://doi.org/10.1177/1533034615588422.

42. van der Veeken J, Oliveira S, Schiffelers RM, Storm G, van Bergen En Henegouwen PM, Roovers RC. Crosstalk Between Epidermal Growth Factor Receptor- and InsulinLike Growth Factor-1 Receptor Signaling: Implications for Cancer Therapy. Current Cancer Drug Targets. 2009; 9:748-60.

43. Karamouzis MV, Konstantinopoulos PA, Papavassiliou AG. Targeting MET as a strategy to overcome crosstalk-related resistance to EGFR inhibitors. Lancet Oncol. 2009; 10:70917. https://doi.org/10.1016/S1470-2045(09)70137-8.

44. Klein B, Falkson G, Smit CF. Advanced ovarian carcinoma. Factors influencing survival. Cancer. 1985; 55:1829-34.

45. Swenerton KD, Hislop TG, Spinelli J, LeRiche JC, Yang N, Boyes DA. Ovarian carcinoma: a multivariate analysis of prognostic factors. Obstet Gynecol. 1985; 65:264-70.

46. Cortez AJ, Tudrej P, Kujawa KA, Lisowska KM. Advances in ovarian cancer therapy. Cancer Chemother Pharmacol. 2018; 81:17-38. https://doi.org/10.1007/s00280-0173501-8.

47. Kalachand R, Hennessy BT, Markman M. Molecular targeted therapy in ovarian cancer: what is on the 
horizon? Drugs. 2011; 71:947-67. https://doi. org/10.2165/11591740-000000000-00000.

48. Ocana A, Vera-Badillo F, Seruga B, Templeton A, Pandiella A, Amir E. HER3 overexpression and survival in solid tumors: a meta-analysis. J Natl Cancer Inst. 2013; 105:26673. https://doi.org/10.1093/jnci/djs501.

49. Ouyang W, Xu L, Huang Z, Guo J, Cai J, Gao X, Wang Z. Role of HER family members in predicting prognoses in epithelial ovarian cancer: a meta-analysis. Tumori. 2015; 101:595-602. https://doi.org/10.5301/tj.5000343.

50. Despierre E, Vergote I, Anderson R, Coens C, Katsaros D, Hirsch FR, Boeckx B, Varella-Garcia M, Ferrero A, RayCoquard I, Berns EM, Casado A, Lambrechts D, et al. Epidermal Growth Factor Receptor (EGFR) Pathway Biomarkers in the Randomized Phase III Trial of Erlotinib Versus Observation in Ovarian Cancer Patients with No Evidence of Disease Progression after First-Line PlatinumBased Chemotherapy. Target Oncol. 2015; 10:583-96. https://doi.org/10.1007/s11523-015-0369-6.

51. Roskoski R Jr. The ErbB/HER receptor protein-tyrosine kinases and cancer. Biochem Biophys Res Commun. 2004; 319:1-11. https://doi.org/10.1016/j.bbrc.2004.04.150.

52. Berchuck A, Rodriguez GC, Kamel A, Dodge RK, Soper JT, Clarke-Pearson DL, Bast RC Jr. Epidermal growth factor receptor expression in normal ovarian epithelium and ovarian cancer. I. Correlation of receptor expression with prognostic factors in patients with ovarian cancer. Am J Obstet Gynecol. 1991; 164:669-74.

53. Henzen-Logmans SC, Berns EM, Klijn JG, van der Burg ME, Foekens JA. Epidermal growth factor receptor in ovarian tumours: correlation of immunohistochemistry with ligand binding assay. Br J Cancer. 1992; 66:1015-21.

54. Rajkumar T, Stamp GW, Hughes CM, Gullick WJ. c-erbB3 protein expression in ovarian cancer. Clin Mol Pathol. 1996; 49:M199-202.

55. Hogdall EV, Christensen L, Kjaer SK, Blaakaer J, Bock JE, Glud E, Norgaard-Pedersen B, Hogdall CK. Distribution of HER-2 overexpression in ovarian carcinoma tissue and its prognostic value in patients with ovarian carcinoma: from the Danish MALOVA Ovarian Cancer Study. Cancer. 2003; 98:66-73. https://doi.org/10.1002/cncr.11476.

56. Steffensen KD, Waldstrom M, Olsen DA, Corydon T, Lorentzen KA, Knudsen HJ, Jeppesen U, Brandslund I, Jakobsen A. Mutant epidermal growth factor receptor in benign, borderline, and malignant ovarian tumors. Clin Cancer Res. 2008; 14:3278-82. https://doi. org/10.1158/1078-0432.CCR-07-4171.

57. Hillig T, Thode J, Breinholt MF, Franzmann MB, Pedersen C, Lund F, Mygind H, Soletormos G, Rudnicki M. Assessing HER2 amplification by IHC, FISH, and real-time polymerase chain reaction analysis (real-time PCR) following LCM in formalin-fixed paraffin embedded tissue from 40 women with ovarian cancer. APMIS. 2012; 120:1000-7. https://doi. org/10.1111/j.1600-0463.2012.02929.x.
58. Paatero I, Lassus H, Junttila TT, Kaskinen M, Butzow R, Elenius K. CYT-1 isoform of ErbB4 is an independent prognostic factor in serous ovarian cancer and selectively promotes ovarian cancer cell growth in vitro. Gynecol Oncol. 2013; 129:179-87. https://doi.org/10.1016/j. ygyno.2012.12.044.

59. Mehner C, Oberg AL, Goergen KM, Kalli KR, Maurer MJ, Nassar A, Goode EL, Keeney GL, Jatoi A, Radisky DC, Radisky ES. EGFR as a prognostic biomarker and therapeutic target in ovarian cancer: evaluation of patient cohort and literature review. Genes Cancer. 2017; 8:589-99. https://doi.org/10.18632/genesandcancer.142.

60. de Graeff P, Crijns AP, Ten Hoor KA, Klip HG, Hollema H, Oien K, Bartlett JM, Wisman GB, de Bock GH, de Vries EG, de Jong S, van der Zee AG. The ErbB signalling pathway: protein expression and prognostic value in epithelial ovarian cancer. Br J Cancer. 2008; 99:341-9. https://doi.org/10.1038/sj.bjc.6604471.

61. Lee CH, Huntsman DG, Cheang MC, Parker RL, Brown L, Hoskins P, Miller D, Gilks CB. Assessment of Her-1, Her-2, And Her-3 expression and Her-2 amplification in advanced stage ovarian carcinoma. Int J Gynecol Pathol. 2005; 24:147-52.

62. Tanner B, Hasenclever D, Stern K, Schormann W, Bezler M, Hermes M, Brulport M, Bauer A, Schiffer IB, Gebhard S, Schmidt M, Steiner E, Sehouli J, et al. ErbB-3 predicts survival in ovarian cancer. J Clin Oncol. 2006; 24:4317-23. https://doi.org/10.1200/JCO.2005.04.8397.

63. Gilmour LM, Macleod KG, McCaig A, Gullick WJ, Smyth JF, Langdon SP. Expression of erbB-4/HER-4 growth factor receptor isoforms in ovarian cancer. Cancer Res. 2001; 61:2169-76.

64. Koumakpayi IH, Diallo JS, Le Page C, Lessard L, Gleave M, Begin LR, Mes-Masson AM, Saad F. Expression and nuclear localization of ErbB3 in prostate cancer. Clin Cancer Res. 2006; 12:2730-7. https://doi.org/10.1158/10780432.CCR-05-2242.

65. Davies S, Holmes A, Lomo L, Steinkamp MP, Kang H, Muller CY, Wilson BS. High incidence of ErbB3, ErbB4, and MET expression in ovarian cancer. Int J Gynecol Pathol. 2014; 33:402-10. https://doi.org/10.1097/ PGP.0000000000000081.

66. Karan Krizanac D, Krasic Arapovic A, Skocibusic S, Pintaric I, Trgo G, Tomic S. CD44 Immunoexpression is Unfavorable Predictor in Ovarian Serous Cancer. Appl Immunohistochem Mol Morphol. 2016 Aug 3. https://doi.org/10.1097/ PAI.0000000000000427. [Epub ahead of print].

67. Zhang J, Chang B, Liu J. CD44 standard form expression is correlated with high-grade and advanced-stage ovarian carcinoma but not prognosis. Hum Pathol. 2013; 44:18829. https://doi.org/10.1016/j.humpath.2013.02.016.

68. Elzarkaa AA, Sabaa BE, Abdelkhalik D, Mansour H, Melis M, Shaalan W, Farouk M, Malik E, Soliman AA. 
Clinical relevance of CD44 surface expression in advanced stage serous epithelial ovarian cancer: a prospective study. J Cancer Res Clin Oncol. 2016; 142:949-58. https://doi. org/10.1007/s00432-016-2116-5.

69. Meng E, Mitra A, Tripathi K, Finan MA, Scalici J, McClellan S, Madeira da Silva L, Reed E, Shevde LA, Palle K, Rocconi RP. ALDH1A1 maintains ovarian cancer stem cell-like properties by altered regulation of cell cycle checkpoint and DNA repair network signaling. PLoS One. 2014; 9:e107142. https://doi.org/10.1371/journal. pone. 0107142 .

70. Somasagara RR, Spencer SM, Tripathi K, Clark DW, Mani C, Madeira da Silva L, Scalici J, Kothayer H, Westwell AD, Rocconi RP, Palle K. RAD6 promotes DNA repair and stem cell signaling in ovarian cancer and is a promising therapeutic target to prevent and treat acquired chemoresistance. Oncogene. 2017; 36:6680-90. https://doi. org/10.1038/onc.2017.279.

71. van Dam PA, Vergote IB, Lowe DG, Watson JV, van Damme P, van der Auwera JC, Shepherd JH. Expression of c-erbB-2, c-myc, and c-ras oncoproteins, insulin-like growth factor receptor I, and epidermal growth factor receptor in ovarian carcinoma. J Clin Pathol. 1994; 47:914-9.

72. An Y, Cai L, Wang Y, Zhu D, Guan Y, Zheng J. Local expression of insulin-like growth factor-I, insulin-like growth factor-I receptor, and estrogen receptor alpha in ovarian cancer. Onkologie. 2009; 32:638-44. https://doi. org/10.1159/000242253.

73. Hirano S, Ito $\mathrm{N}$, Takahashi S, Tamaya $\mathrm{T}$. Clinical implications of insulin-like growth factors through the presence of their binding proteins and receptors expressed in gynecological cancers. Eur J Gynaecol Oncol. 2004; 25:187-91.

74. Liu D, Liu J, Wang C, Lin B, Liu Q, Hao Y, Zhang S, Iwamori $\mathrm{M}$. The stimulation of IGF-1R expression by Lewis(y) antigen provides a powerful development mechanism of epithelial ovarian carcinoma. Int J Mol Sci. 2011; 12:6781-95. https://doi.org/10.3390/ijms12106781. 